\title{
Immunology of Allergic Contact Dermatitis
}

\author{
Ružica Jurakić Tončić', Jasna Lipozenčić', Ivana Martinac' ', Sanja Gregurić \\ 'University Department of Dermatology and Venereology, University Hospital Center \\ Zagreb, School of Medicine University of Zagreb, 2Private dermatologic office Sanja \\ Gregurić, Zagreb, Croatia
}

\author{
Corresponding author: \\ Professor Jasna Lipozenčić, MD, PhD \\ University Department of \\ Dermatology and Venereology \\ University Hospital Center Zagreb \\ School of Medicine University of Zagreb \\ Šalata 4 \\ HR-10000 Zagreb \\ Croatia \\ jasna.lipozencic@zg.htnet.hr
}

Received: April 13, 2010

Accepted: December 1, 2010

\begin{abstract}
SUMMARY Allergic contact dermatitis (ACD) is a T-cell mediated skin inflammation caused by repeated skin exposure to contact allergens. This review summarizes current knowledge on the immunology of ACD. Different phases in ACD are distinguished, i.e. sensitization, elicitation and resolution phases. We discuss contact allergen presentation and the central role of antigen presenting cells during sensitization phase. There is an extremely complex interaction of different kinds of immune cells, such as antigen presenting cells, T, B, NK lymphocytes, keratinocytes (KCs), endothelium, mast cells (MCs) and platelets, and this complex interaction is guided through orchestration of numerous cytokines and chemokines. The role of adaptive immunity has been recognized in contact hypersensitivity but we also discuss the important role of some parts of innate immunity such as natural killer T lymphocytes (NKT) and complement system. Cooperation of innate and adaptive immunity, in this case NK cells and B cells, initiates elicitation phase by complement cascade activation, vasoactive substance release and endothelial activation. $\mathrm{KCs}$ are not only innocent bystanders, on the contrary, they are involved in all phases of $A C D$, from the early phase of initiation through sending "danger" signals and activation of innate immunity, through their role in Langerhans cells (LCs) migration, T-cell trafficking, through the height of the inflammatory phase with direct interactions with epidermotropic T-cells, and finally through the resolution phase with the production of anti-inflammatory cytokines and tolerogenic presentation to effector T-cells. Th-1 and Th-17 cells are the main effector cells responsible for tissue damage. At the end, we point out several subsets of T regulatory cells, which exert down-regulatory function and regulate the magnitude and duration of inflammatory reaction.
\end{abstract}

KEY WORDS: contact allergic dermatitis, immunology, CD8+ cells, contact allergen, hapten

\section{INTRODUCTION}

Skin as the outermost barrier of the human body is the first one to encounter chemicals and physical factors. Two types of contact dermatitis are distinguished: irritant $(C D)$ and allergic contact dermatitis (ACD). ACD is T-cell mediated inflammation of the skin caused by repeated skin exposure to haptens in a sensitized individual (1). ACD requires specific acquired immunity, leading to the development of effector T cells, which mediate skin inflammation (1). Two temporally and spatially dissociated phases in 
the pathophysiology of ACD are distinguished: sensitization and elicitation. Recently, significance of the third, resolution phase has been revealed, during which the restitution of skin occurs (1). Dendritic cells (DCs) have a central role in the pathophysiology through antigen presentation and specific T-cell priming. DCs are the only antigen-presenting cells capable of activating naïve $\mathrm{T}$ lymphocytes; hence they play a crucial role in the induction of adaptive immunity. This results in the creation of specific memory effector T cells, which are redistributed from lymph nodes to circulation and prepared to act in case of antigen challenge (1). Innate immune system is also involved with an important role of natural killer T cells (NKT) and complement system cascade. NKT cells are the first cell subset activated by "danger signals" delivered from damaged KCs (1). KCs are not an innocent bystanders; they are actively involved in all phases of ACD, from the early phase of initiation and sending first "danger" signals and activation of innate immunity, their role in LC migration, T-cell trafficking, through antigen presentation during elicitation phase, and finally through resolution phase with the production of anti-inflammatory cytokines and their role in diminishing the severity of the reaction (2-5).

\section{SENSITIZATION PHASE}

The sensitization phase (also referred to as afferent phase) of ACD occurs after the contact of the hapten and the skin, and lasts for 8-15 days in humans $(6,7)$. This first phase of ACD usually has no clinical consequences, but in some cases may present as primary acute ACD (7).

\section{Contact allergens (haptens)}

All contact allergens share some common features; they have low-molecular weight $(<500 \mathrm{kDa})$, they are not immunogenic by themselves, and they need to bind to epidermal proteins to form haptenprotein complex which is actually immunogenic $(1,6)$. Most of the haptens have lipophilic residues enabling them to cross the barrier, and electrophilic residues, which form covalent bond to the nucleophilic residues of cutaneous proteins $(1,8,9)$. Hapten-protein conjugates are formed via covalent hapten bindings to specific aminoacids of protein carriers (1). Binding to aminoacids causes modification of skin proteins and allows for presentation of new antigenic determinants (1). The majority of contact allergens are not electrophilic and need additional metabolization in vivo $(1,9)$. Transformation from prehaptens and prohaptens occurs upon chemical reactions (oxidation) or due to enzyme activity. Some prehaptens are transformed by UV radiation $(1,9)$. Skin has numerous detoxication enzymes which can modify chemical structure and lead to accumulation of hydrophilic derivatives, which are more easily eliminated from the body $(1,10)$. Haptens are classified into strong and weak haptens. Strong haptens (such as dinitrofluorobenzene) cause reaction in the majority of individuals, while weak haptens are most frequently encountered in humans but cause reaction in a small proportion of individuals $(1,6)$. There is a major difference between reaction to strong and weak haptens: it has been observed that in reaction to strong haptens CD4+ cells do not prevent priming, but participate in the resolution of skin inflammation, whereas in reaction to weak haptens CD4+ regulatory cells totally abrogate the CD8+ cell priming $(1,6,11)$. The inability of weak haptens to sensitize normal individuals may be due to their low irritant/toxic properties (11). Haptens have two important characteristics, proinflammatory properties and immunogenicity $(1,7)$. Their proinflammatory properties provide the first signal that is necessary in innate immunity activation resulting in DC activation, migration and maturation. Their immunogenicity depends on hapten-protein complex presentation in the groove of the MHC class I/II molecules on DC (6).

\section{The role of antigen-presenting cells (APC)}

Primary function of antigen-presenting cells (APC) is to capture, process and present antigens (Ags) to unprimed T cells (12-14). APCs are a heterogeneous population of cells defined by their ability to present antigens (12). DCs have monocytic origin. Immature DCs reside in non-lymphoid tissues. They form a dense network in the skin and capture haptens penetrating skin barrier. Until recently, it has been believed that DCs migrate to lymph nodes where they lose their antigen-processing activity and mature to potent immunostimulatory cells, but today we know that migratory DCs transfer antigen to a lymph node-resident DC population for efficient T cell priming $(12,15,16)$. There are three main DC populations in non-inflamed skin during steady state: epidermal Langerhans cells (LCs), dermal myeloid DCs (dDCs), and dermal plasmacytoid DCs (pDC). During inflammation, another population of dermal DC occurs, "inflammatory" DCs (12).

LCs are epidermal MHC class II DCs specialized in antigen presentation and reside in the suprabasal layers of the epidermis, close to KCs $(6,12,13)$. They typically have Birbeck granule (with still unknown function), Langerin (CD207), which is a membranous C-type lecithin with the function of recognition of mannosylated ligands found on the surface of virus- 
es, bacteria, fungi and protozoa (12). Today, the role of LC is considered controversial $(1,12)$. Until recently, it was assumed that LCs processed antigens locally and migrated to lymph node for efficient Ag presentation, but today it is believed that LCs have the role in inducing and maintaining tolerance to cutaneous antigens $(1,12)$. It has also been shown that ACD response was not completely abrogated despite full ablation of LCs, indicating that several types of DCs are involved in Tcell priming. Also, it has been shown that removal of LCs during the effector phase of ACD in mouse increased the magnitude of inflammatory response $(1,17)$.

Dermal myeloid DCs are a population of DCs residing in the dermis and are considered analogous to interstitial DCs found in connective tissues/stroma of other organs (12). They are able to take up Ags, mature and migrate to draining local lymph nodes and present them to $B$ and T cells (12). Recent data suggest that migratory DCs transfer Ags to resident DCs in lymph node for efficient T-cell priming $(12,15)$. It is important to point out that some of $\mathrm{dDCs}$ can be Langerin+ (12). Therefore, Langerin is definitely not a specific marker for LCs, and it is apparent that various DC subsets express Langerin, notably a particular dermal DC subset, which must not be confused with epidermal LCs during their migration to lymph nodes (1). dDCs have a major role in sensitization, and there is evidence that Langerin+ dDCs can mediate sensitization in the absence of LCs $(1,12)$. It has been shown that Langerin(-) dDCs could have an important role in the induction of ACD $(1,12)$.

pDCs are a unique group of resident cutaneous DCs. While both mDCs and pDCs express high levels of HLA-DR and have Ag-presenting capacity, pDCs are characterized by their ability to produce large amounts of type-1-interferon (IFN) (12).

DCs respond differently to haptens and irritants with their production of cytokines and expression of co-stimulatory molecules (13,18-20). Fully mature DC shows high expression of MHC class II and costimulatory molecules (CD40, CD80, CD86) and also a decreased capacity to internalize antigens (16-20). Up-regulation of CD83 (a specific marker of DC maturation) also occurs and it has been shown that many inflammatory signals can induce DC maturation (16). MHC II is constitutively expressed on LC, and expression of these molecules is strongly up-regulated by haptens and not irritants (20). DC maturation can induce cytokines such as interleukin (IL)-1 $\beta$, tumor necrosis factor (TNF)- $\alpha$, CD40 ligation, expression of IL-12, viral RNA, lipopolysaccharides and contact sensitizers (16-19). Protein haptenization triggers maturation of $\mathrm{DC}$, probably due to reactive cysteine residues and p38 activation. This process is primarily mediated by the activation of p38 mitogen-activated protein kinase (MAPK) and is caused by intracellular redox imbalance induced by contact allergens $(21,22)$. Although MAPK may play a crucial role in the activation of DCs, the upstream signals of p38 MAPK remain undetermined (22).

Migration occurs due to the expression of several families of adhesion molecules, such as E-cadherins, some $\beta$-1-integrins, CD44 isoforms and chemokines $(6,23-26)$. IL 1- $\beta$ and TNF- $a$ both have a role in LC migration to lymph nodes (27). IL-1a, IL-1 $\beta$ and TNF- $\alpha$ levels are increased in contact-allergen sensitized skin. IL-1a is mainly produced by KCs, whereas IL-1 $\beta$ is mainly produced by $L C$, and both IL- $1 a, I L-1 \beta$ can promote LC migration (27). IL-1a is mainly involved in contact allergen-specific-priming, while IL-1 $\beta$ is involved in contact allergen-specific antibody production (27). During migration to lymph nodes, DCs upregulate co-stimulatory molecules on their surface, produce IL-12 and polarize to Th-1/Tc1 (CD8+)-inducing DC phenotype and after the maturation is completed, DC prime hapten-specific naïve T cells in the IL-12 dependent manner $(13,23)$. IL-12 is considered to be important in the generation of allergen-specific T cell response (23). Other surface molecules that are also expressed after the hapten intake are ICAM-1(CD 54) and B7-2 (CD86) (20). IL-1 produced by APC plays a crucial role in Ag-specific T cell priming and clonal expansion, and is necessary for the induction of CD40 ligand on naive T cells (28).

\section{The role of Toll-like receptors: are there similarities between contact and micro- bial antigens?}

The skin is constantly exposed to potential allergens as well as to microbial environmental flora (23). There is a striking similarity between contact allergens and microbial constituents that are sensed by Toll-like receptors (TLR) and activation of NF-KB and MAPKs (29). Inflammatory reaction in ACD resembles inflammatory reaction to microbial pathogens. There is evidence that Toll-like receptor 4 (TLR4) has a role in the induction of ACD, which occurs in IL-12-independent pathway (23). It has also been shown that TLR4 and IL-12 can replace each other during ACD induction, and the loss of IL-12 function leads to enhanced allergic response, mediated by TLR4. This augmentation may be explained by the loss of IL-12 inhibitory effect on IL-17-producing CD8+ cells participating in elicitation phase of ACD $(23,30)$. The exact role of TLR4 is not fully understood, but it seems that TLR4 might be required for the induction of cytokines in DC with 
impaired IL-12 function. It has also been shown that TLR9 (receptor for microbial DNA for certain viruses and bacteria) can take place of TLR4 and it is possible that infections may provide TLR ligands that support/ replace TLR4 function during sensitization to contact allergens (23). A possible candidate cytokine induced by TLR4 activation is IL-23 (a member of IL-12 family). IL-23 (like IL-12) participates in DC activation and enhances hypersensitivity reaction (23). IL-23 stimulates (while IL-12 inhibits) IL-17-producing CD8+ cells. TLR2 is important for Th-1 response to cutaneous antigens. Skin is colonized with bacteria, which can be the source of TLR2 ligands (23). TLR2 promotes the IFN$\gamma$ response to cutaneously introduced antigens (31). There is also evidence that NKT production of IL-4 is TLR-dependent and that it has a role in the initiation of contact sensitivity (32). Recent study data provide evidence that heat shock proteins (HSP27 and HSP70) form a link between adaptive and innate immunity during early stages of contact sensitivity. Their interaction with TLR4 increases the production of cytokines known to enhance Ag presentation by T cells (33).

\section{Hapten specific $\mathbf{T}$ cell activation requires three signals}

Immature DCs sample and process Ags and once activated become capable of activating naïve $T$ cells and directing their differentiation and polarization to different types of effector T lymphocytes. This occurs in three steps. Hapten determinants provide the first necessary signal in T cell activation (Fig. 1). Specific antigen recognition occurs after the interaction of $\mathrm{T}$ cell receptor (TCR) and hapten-peptide complex presented by $\mathrm{MHC}$ molecule (1). T cells react with

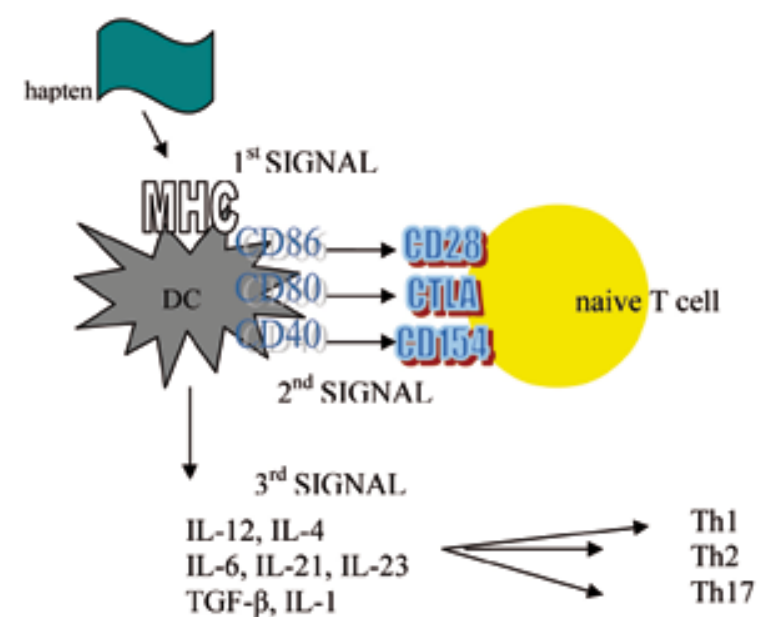

Figure 1. Three necessary signals in hapten specific activation.
MHC-associated peptides, not with covalently modified MHC molecules. TCR interacts with hapten and partially with MHC molecule (1). It is likely that some haptenated proteins are endocytosed, processed and presented by MHC II. External antigens are endocytosed and processed on MHC II class molecules to CD4+ cells, while internal cytoplasmic antigens are processed by endogenous pathway and presented on MHC I class molecules to CD8+ cells. External antigens can also enter the endogenous pathway and this refers to contact sensitizers, viral antigens, drugs and auto-antigens (34). Haptens are also able to interact directly with peptides which are already in the groove of $\mathrm{MHC}$ II and MHC I molecules, and CD8+ and CD4+ could be activated in the lymph nodes by skin DC expressing haptenated peptides (34). There are differences between delayed type reaction to proteins and cellular antigens, proteins are presented by MHC II and the former by $\mathrm{MHCI}(34,35)$. Liposoluble haptens can penetrate the cytosol of DC and bind to cytoplasmic proteins, and follow the endogenous pathway resulting in $\mathrm{MHC}$ class I-restricted antigen presentation.

DCs deliver the second necessary signal in the activation of specific $T$ cells with co-stimulatory molecule expression (1,35) (Fig. 1). Important co-stimulatory molecules expressed by DCs are members of the B7 family: B7-1 (CD80), B7-2 (CD86) and CD40 (1, 35-39). CD80 and CD86 interact with T-cell molecules CD28 and CTLA-4 (CD125). CD28 is constitutively expressed on naïve T cells (1). During maturation, DCs up-regulate CD80 and CD86 expression, and it seems that CD86 is the principal ligand for CD28 involved in second signal. CD28 ligation is mandatory for the development of ACD (1). B7-1(CD 80) and B7-2 (CD 86) deliver different co-stimulatory signals to $T$ cells during antigen presentation. Data suggest that KCderived co-stimulation mediated by B7-1 (not B7-2) results in the emergence of Th-2-lymphocyte immune responses to Th- 1 haptens. It has been noted that human KCs express B7-1-like molecules in certain inflammatory skin diseases and this may be important in understanding the pathophysiology of Th2-lymphocyte-mediated skin diseases $(39,40)$.

The interaction between a member of TNFR superfamily ligand OX-40L and OX-40 (CD 134) expressed by activated T cells induces CD80 and CD86 overexpression on DCs and therefore better T cell activation $(1,28,41)$. Some others pairs of co-stimulatory molecules also participate in $\mathrm{T}$ cell activation, such as those from TNF/TNF receptor family: CD40/CD40 ligand and RANK/RANK ligand. These interactions result in up-regulation of OX-40 ligand on DCs (1).

APCs present $\mathrm{Ag}$ in complex with MHC II molecules to naive $T$ cells resulting in CD154 expression 
on T cells, with the final result of co-stimulatory activity expression on APCs. At this time, co-stimulatory signal is received by $\mathrm{T}$ cells via CD28/CTLA-4 interaction resulting in complete $T$ cell activation. Tight regulation of this interaction prevents activation of unwanted bystander T cells and only some T cells will be activated (and therefore protected against the autoimmune response) (42-44). T cell engagement of CD40 co-stimulatory molecule expressed by APCs is required for many $T$ cell responses $(40,42)$. CD154 is a CD40 ligand and is rapidly expressed on CD4+ cells during cellular activation, and has a crucial role in CD4+ T cell dependent humoral responses. CD40/ CD154 (CD40L) interaction is involved in a broad variety of immune responses: expression of adhesion molecules, cytokines and apoptotic mediators, and is found on T- and B-lymphocytes, DCs, monocytes, eosinophils and basophils (43). This interaction plays a role in early signaling events where interactions of this kind are required to induce expression of co-stimulatory molecules on APCs (42). It can also up-regulate co-stimulatory molecules, activate APCs, influence T cell priming and $T$ cell mediated functions, and thus participate in the process of chronic inflammatory disease and therefore governs both the magnitude and quality of humoral and cell-mediated immunity $(44,45)$. Also, some studies have shown the role of this interaction in DC longevity and T cell persistence (46). On the other hand, the role of CD40/CD154 interaction is not quite clear during the development of CD8+ cells, but some studies indicated that this interaction might be necessary in the development of certain CD8+ T cell responses. It has been proven that development of hapten specific Th-1 effector CD4+ cells requires both CD40/CD154 interaction and IL-12, whereas the development of IFN $y$ producing effector CD8+ cells can occur independently of these pathways $(40,47)$.

In order to avoid excessive T-cell activation, critical negative signals are also delivered and involve couples of B7-family, such as CD80-CD86/CTLA-4. This interaction is a predominant inhibitory pathway (1). CTLA-4 has a synergistic action with PD-1, B7-H3 or B7-H4 $(1,37,38)$.

DCs produce cytokines and therefore provide the third necessary signal for T cell polarization (1) (Fig. 2). After DC maturation is completed, DC prime haptenspecific naïve T cells in IL-12 dependent manner, giving rise to allergen-specific CD8+ cells which express skin-specific homing receptors (23). The following $T$ cell differentiation depends on the type of cytokines secreted by DC $(1,48)$ (Fig. 2). Their polarization can be driven into Th-1, Th-2 or Th-17 depending on IL12 , IL-4, or cocktail of IL-6/IL-21/IL-23+/-TGF $\beta$, or IL-1 are secreted. Th- 1 cells secrete IFN- $\gamma$, IL-2, TNF- $a$, Th-2 cells IL-4, IL-10, IL-13, IL-5M and Th-17 cells IL-17A, IL17F, IL-21 and IL-22. Third signal has the essential role in $T$ cell activation, and if it does not occur, activation of $T$ cells fails $(35,49)$.

The equilibrium of CD4+ and CD8+ depends on the identity of the allergen (23). Numerous studies have shown that CD8+ cells are the main effector cells, while CD4+ are mainly down-regulatory cells $(34,35)$. Optimal activation of naive CD8+ requires signals received by CD4+ cells, but in reaction to strong haptens CD8+ cells do not require this help and CD40/CD40L involvement is unlikely (34). Ag-specific CD8+ cells can be induced without CD4+ help due to the hapten proinflammatory properties and ability to generate danger signals and activate DC $(1,50)$. Some antigens have the intrinsic ability to induce DC maturation and therefore bypass the need of CD4+ help via CD40 activation (34).

\section{Memory and effector T cells}

T cell priming results in the formation of Ag-specific T cells. As the result, short-lived effector T cells and long-lived memory $T$ cells are generated that reach peripheral tissue in order to participate in immune responses and immune surveillance. Relocation of effector and memory T cells is non-random, due to tissue-specific "address codes" that allow for proper tissue homing. This process involves adhesion molecules, including selectins, integrins, and corresponding vascular ligands as well as the large family of chemokines and their receptors (51). A fraction of primed T lymphocytes persists as circulating memory

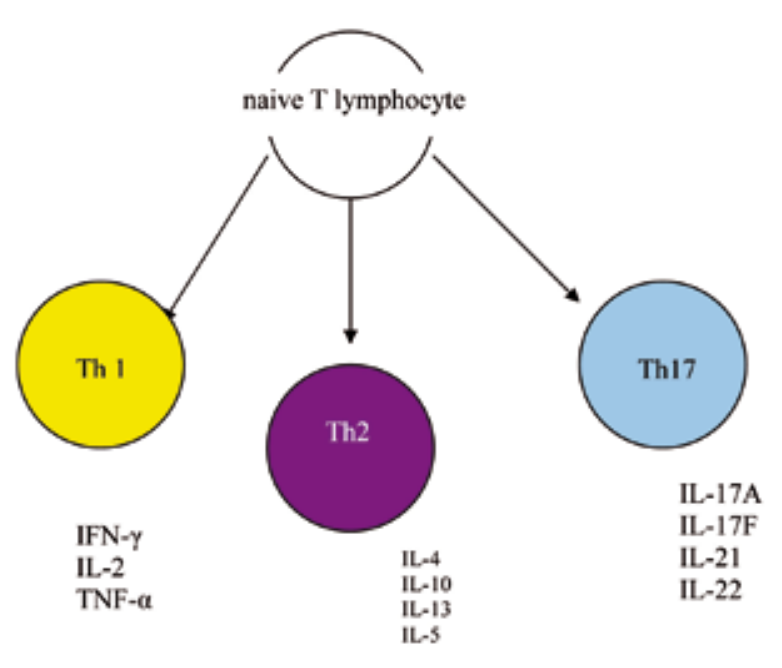

Figure 2. Dendritic cells elicit third signal by excreting cytokines and driving $T$ cell polarization into one of three effector T cells 
cells and can confer protection and give, upon secondary challenge, a qualitatively different and quantitatively enhanced response (52).

The expression of CCR7, a chemokine receptor that controls homing to secondary lymphoid organs, divides human memory $T$ cells into two functionally distinct subsets. CCR7 is characteristic of naïve and central memory T cells (51). The CCR7(+) cells, named central memory (TCM) and CCR7(-), named effector memory T cells (TEM), differentiate in a stepwise fashion from naïve $T$ cells, persist for years after immunization and allow for division of labor in the memory response (51). CCR7(+) cells are called central memory cells and re-circulate from blood to lymph node but they do not have the possibility to enter the skin. CCR7(+) cells also may act as innate cells after Ag-challenge due to their strong release of IFN- $\gamma$ and CCL5, and increase the efficacy of T cell response $(1,53)$.

CCR7(-) memory cells are called effector memory cells and express receptors for migration to inflamed tissues and display immediate effector function. In contrast, CCR7(+) memory cells express lymph-node homing receptors and lack immediate effector function, but efficiently stimulate DCs and differentiate into CCR7(-) effector cells upon secondary stimulation (52). The long-lived memory T cells are subdivided into CCR7- negative effector memory T cells and peripheral immune surveillance $T$ cells. The latter are an extraordinarily large subset of memory $T$ cells with primary residence in normal (healthy) peripheral tissues (51). It appears that peripheral immune surveillance $T$ cells provide immediate protection locally at the site of pathogen entry (51).

Teff and Tem found in murine skin express chemokine receptors (CCR4, CCR10, a4 $\beta 1$ integrin) and cutaneous lymphocyte antigen (CLA) crucial for efficient T-cell homing into the skin $(1,54)$. CLA is considered to be homing receptor for T cells with skin tropism (54). It binds to E-selectin, an adhesion molecule expressed on activated endothelium as a response to the action of IL-1 and TNF-a (54). Interaction of CLA with E-selectin mediates lymphocyte adhesion (54). There is also evidence for the role of glycosyltransferases in the process of skin homing, named alpha $(1,3)$ fucosyltransferases, FucTVII and FucTIV (55). IL-12 is a relevant CLA inducer, since IL-12 induces synthesis of FucTVII on T cells undergoing naïve to memory transition (54). IL4, on the other hand, inhibits FucTVII expression (54).

\section{ELICITATION PHASE}

Elicitation phase is also known as efferent or challenge phase $(1,6)$. Upon subsequent skin contact with the hapten, specific T lymphocytes are activated and trigger inflammatory process responsible for cutaneous lesions (6). One of the important characteristics of memory CD8+ cell is their capacity to display immediate effector functions following Ag re-exposure $(53,56)$. This process lasts for several days and progressively decreases upon physiological down-regulating mechanisms (6). A memory response to $\mathrm{Ag}$ is much faster than the primary response $(1,6,53)$. Infiltration of hapten-specific effector and memory T cells causes local inflammatory response $24-72$ h later $(6,23)$. Recruitment of lymphocytes into inflamed skin is a multistep process and involves recognition of vascular endothelial cells and extravasations $(57,58)$. There is a sequentional infiltration of the skin, CD8+ cells enter first, and then CD4+ cells due to differential expression of homing-receptors and sequentional expression of chemokines (56-60). Th-1 cells express more functional ligands for E- and P-selectin than Th-2 cells, $\mathrm{IL}-12$ is required for expression of P-selectin ligand on both CD8+ and CD4+(61,62). CD8+ cells infiltrate skin $9 \mathrm{~h}$ after hapten re-exposure, whereas CD4+ cells are recruited after $24 \mathrm{~h}$ and this fact is associated with

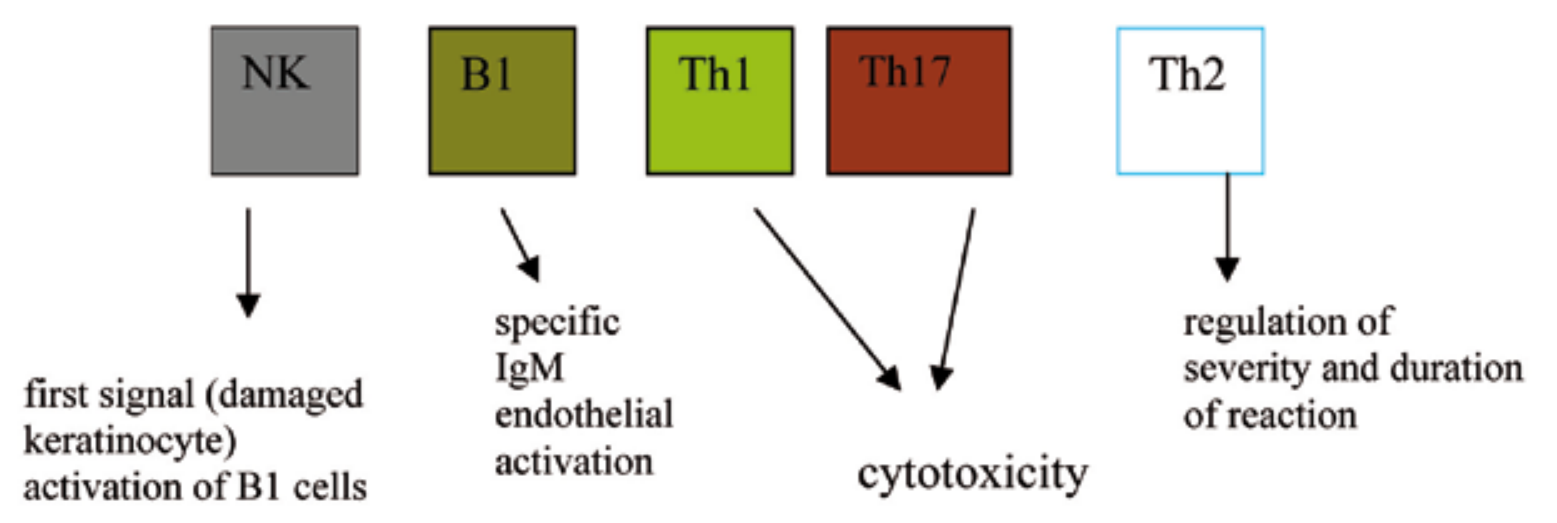

Figure 3. Effector cells during elicitation phase. 
diminishing the reaction severity (57). Secretion of Th2 cell attracting chemokines, such as CCL1 (I-309, CCR ligand) by activated Th-1 cells, or CCL22 (macrophagederived chemokine (MDC), CCR4 ligand) by skin cells might serve to recruit CCR4/CC8-expressing Th- 2 cells for down-regulation of Th-1 mediated inflammatory response (63). Activated T cells produce type I cytokines (IFN- $\gamma$ ) and activate skin resident cells resulting in cytokine and chemokine production with following recruitment of polymorphous cellular infiltrate (34).

Very few recruited Ag-specific effector T cells need to be activated to produce Th-1 cytokines like IFN- $\gamma$ and produce local inflammatory response (64). IFN- $\gamma$ is a key cytokine in local expression of inflammation during the first $24 \mathrm{~h}$, and this inflammation is mediated by the production of KC-derived chemokines (such as IP-10, MIG, I-Tac acting on CXCR3 leukocyte chemokine receptors) with resulting activation of nonspecific bonemarrow-derived leukocytes and constitution of perivascular infiltrate $(60,64)$. MCP-1 and RANTES are the dominant monocyte/macrophage chemoattractants expressed during the elicitation phase (63). Furthermore, the lymphocyte attractant chemokines IP-10, MIG, MCP-1, MDC, RANTES, PARC and TARC are highly and differentially expressed during elicitation phase of ACD (63). There is an obvious redundancy of chemokines for monocytes and lymphocytes (63). IFN- $\gamma$ induces MIG and IP-10 expression (63).

\section{Three steps during elicitation phase}

Both subsets of T cells, CD4+ and CD8+, mediate skin inflammatory reaction, however, more studies have shown that hapten-specific CD8+ cells can mediate reaction without CD4+ cells (6). CD8+ cells have the main effector role during elicitation phase, whereas CD4+ can have pathogenic and regulatory role. There are three steps in the development of elicitation phase of ACD (1). First step includes early recruitment of $\mathrm{CD} 8+$ cells and this is initiated via endothelial activation due to hapten-induced skin inflammation (1). Second step is activation of hapten-specific cells, and activation of skin-resident cells and cytokine and chemokine production. Third step is arrival of leukocytes to the skin, especially macrophages and neutrophils, and development of clinically observed reaction (1).

\section{Role of natural killer T lymphocytes in the initiation of elicitation phase (NK T cells)}

After Ag challenge, innate immunity mechanisms are activated. NKT cells are activated within the first hour following sensitization and are the first-acting required lymphocyte subset $(32,64-68)$. They express
aß-TCR, which is semi-invariant and recognizes glycolipids and binds some hydrophobic peptides (64). NKT are activated by hydrophobic substances such as endogenous glycolipids released from damaged skin during the first hour (Fig. 4). Lipid binding and presentation via $\mathrm{MHCl}$ complex results in the production of several cytokines, mostly IL-4 and/or IFN- $\gamma$ (65). Their activation results in prompt IL-4 production and this rapid IL-4 release has the crucial role in B1 cells activation causing migration of $B 1$ cells to the spleen and lymph nodes $(64,66,67)$ (Fig. 4). IL-4 is produced preferentially by hepatic NKT cells within 7 minutes of immunization and acts via IL-4 receptors and signal transducer and activator of transcription of (STAT)- 6 signaling to stimulate B1 cells (68). This early production of IL-4 is transient and ceases in $1 \mathrm{~h} \mathrm{(68).}$

\section{The role of B cells, complement system, mast cells and platelets, and endothelial activation}

B1 cells are activated rapidly during the first day after immunization $(69,70)$. They initiate T cell elicitation via hapten specific IgM antibody production (Fig. 4 ) $(69,70)$. Local hapten-complex binds to IgMantibody derived from circulation (previously produced by distant B1 cells) and this complex activates complement system resulting in the production of C5a (60). Complement system is an important component of innate immunity and is involved in early protective immune responses, before acquired $\mathrm{T}$ or $B$ cell immunity and local complement activation is involved in the crucial early initiating events and in initial T cell recruitment $(71,72)$. Mast cells $(M C s)$ and platelets express functional $\mathrm{C} 5 \mathrm{a}$ receptor $(\mathrm{C} 5 \mathrm{aR})$ and C5a causes release of vasoactive substances such as serotonin (5-HT) and TNF-a (Fig. 4) (1,64,73-77).

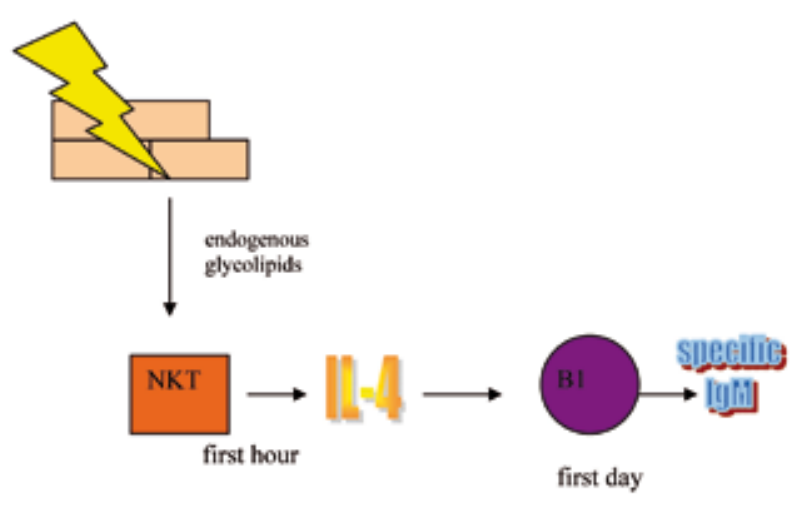

Figure 4. Damaged keratinocytes give the first (,danger“) signal and activate natural killer $\mathrm{T}$ lymphocytes which produce IL-4 resulting in B1 activation and production of specific lgM. 
Also, C5a is chemoattractant for T cells and macrophages since they express $\mathrm{C} 5 \mathrm{a}$ receptors (C5aR) (71). Human platelets can initiate T cell-dependent responses through lgE- antibody, mediated by $5-\mathrm{HT}$ released from the platelets in an $\mathrm{Ag}$-specific manner (74). Blocking of the high affinity lgE receptor on MCs can suppress contact hypersensitivity response (75). In later responses, B1 cell response fades away and B2 cells become responsible through IgG2-mediated complement activation (64). Even $\operatorname{lgE}$ and $\lg G 1$ are able to activate MCs and release vasoactive mediators in complement-independent way (64). HT-5 and TNF-a release leads to local activation of endothelium $(78,79)$. Endothelial activation is necessary for $\mathrm{T}$ cell recruitment and involves both Ag-nonspecific and Ag-specific events (60). Non-specific local irritation by the chemically reactive hapten can recruit $T$ cells by KC activation and production of endotheliumactivating cytokines such as IL-1 and TNF-a $(76,77)$. Ag-specific CS-initiating cascade occurs within $2 \mathrm{~h}$ of Ag challenge, and the participating components are mast cells and platelets (76).

\section{The role of cytokines, chemokines and adhesion molecules in T-cell recruitment}

There is an early and a late phase of leukocyte recruitment. Specific T cells emigrate from lymph node, enter the blood and recirculate into the skin (34). Leukocyte adhesion to endothelium is the first step in their migration to tissues (79). Recruitment of effector cells is orchestrated by sequential and coordinated release of cytokines and chemokines (1). Leukocytes require a series of adhesion events: rolling, firm adhesion and migration into inflamed regions $(77,80)$. Memory CD45R0+ T cells express skinhoming capabilities, and the elements that facilitate their tropism for the skin are different adhesion molecules, enzymes and chemokine receptors (54). 5HT and TNF-a released from MCs and platelets activate the endothelium and cause expression of adhesion molecules such as VCAM-1, ICAM-1, P-selectin and E-selectin (79). Cytokine-activated KCs are an important source of chemotactic factors that direct the recruitment of specific leukocyte populations and thus regulate the quality, magnitude and duration of the inflammatory response (80-82). Proinflammatory cytokines such as IL-1 and TNF-a play a significant role and the reaction is very suppressed in mice deficient in these cytokines $(1,27,77)$. Adhesion molecules such as ICAM-1, VCAM-1, E- and P-selectin on vascular endothelium are up-regulated by IL-1 and TNF-a during elicitation phase and facilitate leukocyte rolling and firm adhesion at inflammatory sites $(54,77,79,80,83)$. Ag-specific release of TNF-a from MCs induces VCAM-
1 and ICAM-1 expression on the luminal surface of local endothelium at $4 \mathrm{~h}$ after $\mathrm{Ag}$ challenge (79). ICAM 1 and VCAM-1 are believed to be involved in firm adhesion of rolling leukocytes on endothelial cells. a-integrin binds to VCAM-1 and initiates interaction of leukocytes with endothelial cells (79). Haptens are able to induce rapid expression of E-selectin, P-selectin, VCAM-1 and ICAM-1 on the surface of endothelial cells (57). These adhesion molecules mediate rolling, adhesion and extravasation of leukocytes expressing CLA or P-selectin ligands into the skin. The interactions between CLA/ E-selectin, VLA-4/VCAM-1 and LFA-1/ICAM are necessary for transendothelial migration of CLA+ T cells $(54,84)$.

Selectins are important for adhesion, tethering and rolling (54). Molecular mechanisms mediating early leukocyte recruitment are E- and P-selectin, and late phase has a different adhesive profile (mainly a4integrin) (85). CLA antigen is a ligand for E-selectin, an adhesion molecule that is induced on endothelium under inflammatory conditions in response to IL-1 and TNF-a (54). E-selectin and P-selectin are responsible for the early CD4+ recruitment (within $2 \mathrm{~h}$ ) and produce factors that either directly or indirectly modify the endothelium to permit subsequent latephase recruitment. Inhibition of the early recruitment of CD4+ cells eliminates the late response, therefore CD4+ cells home to skin via P-selectin and E-selectin within an early phase and induce the late phase response (85).

Chemokines are a family of proteins mainly involved in cellular trafficking and therefore play an essential role in recruitment of leukocytes to inflammatory sites $(53,54)$. Their function is to allow integrin recognition by their counter endothelium receptors, and they are responsible for lymphocyte morphology change during diapedesis (54).

Effector cells are directed to skin via up-regulation of CCL2, CCL5, CCL20, CCL22 and CCL27 in the first 6$12 \mathrm{~h}$ after hapten challenge with concomitant infiltration of mononuclear cells (1).

TCR-engagement of effector cells induces release of type 1 cytokines such as IFN- $\gamma$, TNF- $\alpha$, IL-4 and IL-17, which stimulate the secretion of IP-10 (CXCL10), CXCL11, CXCL9, the ligands of CXCR3, CXCl8, CCL17(TARC), CCL18(PARC) or of IL-1, IL-6, TNF-a, GM-CSF by KCs, MCs or other skin cells (82). IFN- $\gamma$ is a potent inducer of IP-10 (IFN- $\gamma$-inducible protein 10) and plays an important role in trafficking of effector Th-1 cells to inflammatory sites (86).

Several chemokine-receptors have been observed on CLA+T cells: CXCR2, CCR4, CCR6, CXCR3 and CCR10 (86-91). Chemokines regulate the lymphocyte traffic 
in part by triggering arrest of rolling lymphocytes, and among a variety of chemokines CCL-2, MCP-1 (monocyte chemotactic protein-1), CCR-2 ligand are important $(57,92-96)$.

$\mathrm{KC}$ derived MCP-1 can recruit dendritic, LCs, monocytes and memory $T$ cells (94-96). It has also been shown that MCP-1 not only accelerates LC migration from skin to $L N$ after sensitization with haptens but also up-regulates the I-Ad and B-7 expression, resulting in enhanced T cell activation and CHS (96).

CCR6, a CC chemokine receptor which interacts with KC expressed CCL20 is expressed by epidermal LC and effector/memory T lymphocytes (97). CCR6 is critical for directing immune cell migration into the skin during contact hypersensitivity (97). After hapten challenge, DCs increase CCR7 expression and decrease CCR6 expression during DC maturation and migration to lymph node to prime $T$ cells. In lymph node, DCs can re-express CCR- 6 , which may play a role in directing them back into the circulation (97).

Other potential receptors expressed on skin-homing T lymphocytes include CCR4 and CCR10. CCR10 might be the most interesting chemokine due to the fact that CCR10 ligand CTACK/CCL27 (cutaneous T-cell attracting chemokine) is mainly produced by KCs and is up-regulated in inflammation (92). CTACK/ CCL27 is constitutively expressed by epidermal KCs (1). Expression of CCR10 is restricted for CLA+ CD4+ cells (92). CCR10 ligand CCL27 is produced by KCs in inflamed skin $(97,98)$.

TARC (the chemokine thymus and activation regulated chemokine; (CL17) is displayed by cutaneous vessels and triggers vascular arrest of skin homing memory T cells which have TARC receptor CCR4 (98). CTACK (CCL27) is expressed by KCs and also assists in recruitment of $T$ cells to the skin (98). In chronic inflammatory process, CD4+ cells express E-selectin binding activity (a marker for skin homing memory cells) in lymph nodes and E-selectin (+)T cells migrate efficiently to TARC and CTACK. It has also been shown that CTACK and CCR4 can both support homing of T cells to the skin and one or both of them is required in cutaneous contact hypersensitivity (98).

Memory CD8+ cells produce high levels of RANTES protein immediately after TCR triggering. RANTES is a C-C chemokine (also called C-C chemokine ligand 5) and binds to three receptors: CCR1, CCR3 and CCR5 (53). Increased production of RANTES protein by CD8+ cells mainly relies on pre-stored RANTES mRNA (53). RANTES is a proinflammatory chemokine involved in chemoattraction of a number of types of effector cells. It acts on CD8+ cells and increases their IFN- $\gamma$ production or their cytotoxic activity via up-regulation of Fas ligand. RANTES can act on immature DC inducing the production of TNF-a, which participates in maturation of DC (53).

\section{CD8+ cells are the main effector $T$ cell sub- set in contact allergic dermatitis}

Many investigators have confirmed that haptenspecific CD8+ cells are the main effector cells $(1,11)$. Two different helper T cell subsets, Th-1 and Th-17, mediate tissue damage and inflammation (99) (Fig. 3). Although most recent studies have emphasized the major effector role of CD8+ cells, it cannot be excluded that CD4+ cells could participate appreciably in the inflammation (82). There are some conflicting results on the role of Th- 2 cells; some authors indicated suppressive, some enhancing or no effect (82). Finally, it seems that IL-10 producing CD4+ cells are primarily involved in the regulation of ACD. Th- 1 cells produce high amounts IFN- $\gamma$ and TNF- $a$, display predominant effector functions and may cooperate with CD8+ cells in amplifying the inflammatory response (82).

Th-17 cells are the third effector T cell subset and produce IL-17, IL-17F and IL-22 resulting in massive tissue reaction due to the broad distribution of IL17 and IL-22 receptors in the tissue (100-105) (Fig. 3). TGF- $\beta$, together with IL-6 and IL-21, initiates differentiation, while IL-23 stabilizes the generation of Th-17 cells (105). There is evidence for the role of IL-23 and Th-17 in human allergic dermatitis (103). Th-17 cell differentiation occurs in close association with CD4+CD25+Foxp3+ cells with participation of TGF- $\beta$ (104). Since TGF- $\beta$ is essential for both Th-17 and Tregs, a developmental link between these two subsets was suggested, but these two subsets have opposite functions: Th-17 cells are highly pathogenic during inflammatory process, whereas Tregs have a regulatory function (105).

Prostaglandins, particularly prostaglandin E2 (PGE2), have an important role during inflammation. It has been shown that PGE2- EP4 signaling promotes immune inflammation through Th-1 cell differentiation and Th-17 cell expansion (100). PGE2 acts via prostaglandin receptor EP2- and EP4-mediated signaling and CAMP pathways to up-regulate IL-23 and IL-1 receptor expression. While enhancing Th-17 cytokine expression mainly through EP2, PGE2 differentially regulates interferon (IFN) $-\gamma$ production and inhibits production of the antiinflammatory cytokine IL-10 in Th-17 cells predominantly through EP4. Also, PGE2 is required for IL-17 production in the presence of antigen-presenting cells $(101,102)$. 


\section{Cytotoxicity of T cells}

During elicitation phase, $\mathrm{KCs}$ act as antigen presenting cells due to the fact that MHC I molecules are expressed on all cells (33). It is possible that haptens could be expressed as haptenated peptides by different skin types. Apoptosis of KC but not LC occurs during the elicitation phase (57). LCs are not relevant APCs during elicitation phase, but have a role in down-regulation (17). Although LCs are involved in Ag presentation during the sensitization phase, their role during the elicitation phase still remains unclear $(1,12,17)$. In fact, they migrate away from the site of Ag application and this is an argument against their role in active participation in T cell activation (57).

Cytotoxicity is the main characteristic of the CD8+ effector cells and it occurs via two independent mechanisms. Secretory pathway involves perforin and granzymes released from granules; non-secretory pathway involves Fas-ligand-up-regulated activation resulting in apoptosis-induced Fas molecule on the target cell. The perforin/granzyme pathway does not need expression of specific susceptibility molecules on the target cell and potentially allows for lysis of all cells, whereas Fas/FasL mechanism requires Fas expression on the target cell in order to be sensitive to Fas-induced apoptosis (82). Both pathways have been observed in contact hypersensitivity and absence of one mechanism can compensate for the other (34). Therefore, there are two types of cytotoxic lymphocytes (CTL): type I CTL, which kill the target cell through perforin/granzyme-dependent mechanism and type II CTL, which require ICAM-1-derived signals to activate both Fas/FasL and perforin-dependent pathways (82).

Fas-induced KC apoptosis caused by skin-infiltrating $T$ cells is a major mechanism in the pathogenesis of eczematous dermatitis (106). It is possible that activated T cells use granule-mediated killing with perforin/granzyme, but authors could not detect perforin and granzyme in lesional skin of ACD (106).

$K C$, under the influence of lymphocyte-derived cytokines such as IFN- $\gamma$ and IL-17, also express MHC II and adhesion molecules crucial for $T$ cell function and retention in the epidermis. Newly recruited activated CD8+ cells release IFN- $\gamma$ and TNF- $a$, both potent KC activators, and promote up-regulation of ICAM-1, MHC II and release of CXCL-9, CXCL-10 and CXCL-11 (1). CD8+ cells exert their cytotoxic activity on both resting and IFN- $\gamma$-activated $\mathrm{KC}$, whereas Th- 1 cells kill exclusively KCs previously exposed to IFN- $\gamma$. Moreover, IFN- $\gamma$ up-regulates Fas expression and renders $\mathrm{KC}$ sensitive to Fas-mediated lysis (82). Fas-signaling activates caspase enzyme cascade and ultimately results in apoptosis (106). Most notably, apoptosis oc- curs in suprabasal epidermis. Damage to KCs results in loss of intercellular cohesion (acantholysis) and fluid influx from dermis (spongiosis). FasL expression is usually limited to activated T cells, natural killer cells and cells of certain immunologically privileged sites. Fas mediated apoptosis can be mediated by CD4+ and CD8+ cells (106). While CD8+ cells exert their cytotoxic activity on both resting and IFN- $\gamma$-activated $\mathrm{KCs}$, Th-1 cells kill exclusively KCs previously exposed to IFN- $\gamma$. IFN- $\gamma$ treatment renders KCs susceptible to Th-1, but not Th-2 (82). Among CD4+ T cells, only the Th-1 subset is able to kill KCs but exclusively after MHC II induction of IFN- $\gamma$, and may cooperate with CD8+ cells. In contrast, KCs appear to be resistant to Th-2-mediated cytotoxicity (82).

\section{Regulatory cells (Tregs)}

The role of regulatory cells is to maintain tolerance and to gain control over the inflammatory responses by regulating magnitude and duration of contact hypersensitivity response $(20,23,52,64)$. CD4+ cells have been shown to have a pathogenic role, but they also have a regulatory function. In humans, both regulatory and pathogenic CD4+ cells exist. Specialized CD4+ T cells perform immunomodulatory function through release of suppressive cytokines (Fig. 5) (107). CD4+ cells down-regulate reaction and act during both sensitization and elicitation phase, limiting the size of CD8+ pool or modifying their functional properties in lymph node during the sensitization phase and cells regulating CD8+ cell-mediated immune responses by restricting effector $T$ cell development through a Fas ligand-dependent mechanism $(34,58,108,109)$. Some studies suggested that CD4+ cells might suppress CD8+ cells by producing IL-4, IL-5 and IL-10 (35). Balance between regulatory and effector mechanisms may be relevant for both allergic and autoimmune diseases, and despite long retention of hapten in the skin, inflammatory reaction is self-limited, suggesting the role of IL-10 (56).

There are basically two distinct subsets of Tregs: antigen-specific Tregs and naturally occurring CD4+CD25+ Tregs (107) (Fig. 5). They are further divided into three major subsets of Tregs: 1$) \operatorname{Tr} 1$ cells with IL-10 secretion, 2) Th3 cells withTGF- $\beta$ secretion, and 3 ) naturally occurring CD4+CD25+ T cells (Figs. 5 and 6) (107). Few recent reports suggest the existence of $\mathrm{T}$ regulatory activity also among the CD8+ population (3). There is also evidence for the regulatory role of $\mathrm{B}$ cells, which exert their role through the production of IL-10 $(110,111)$.

Ag-specific Tregs (secondary suppressor) are further divided into two subgroups: $\operatorname{Tr} 1$ and Th3. The key modulation cytokines are IL-10 and TGF- $\beta$. 
$\operatorname{Tr} 1$ express CLA and are easily recruited at the site of hapten re-exposure where they can rapidly secrete high amounts of IL-10, and impair monocyte and DC function with the result of decreased $T$ cell activation $(56,112)$. IL-10 is a potent anti-inflammatory cytokine and can down-regulate immune responses mainly through monocyte inhibition (monocyte release of TNF-a) and DC presenting capacity $(56,112)$. IL-10 promotes class II MHC expression on DC (56). Additional mechanism could be that IL-10 converts DCs into tolerogenic APC (113) (Fig. 6). It has been shown that hypersensitivity reaction to hapten is enhanced with IL-12, and diminished with IL-10 (56). Tr1 cells control activation of naïve and memory $T$ cells, and suppress Th-1 response and reduce capacity of DCs to induce Ag-specific proliferation of T cells (112-118). IL-10 down-regulates Th-1 cytokine response, but not Th-2 cytokine response (112).

Th3 cells are TGF- $\beta$ producing CD4+ cells $(107,119,120)$. Regulatory Th3 are a unique subset of T cells induced by orally administered Ag. They help IgA production and have suppressive effects on Th-1 and Th- 2 cells. Th3-induction is Ag-specific, but their suppressive effect is Ag-nonspecific and mediated through TGF- $\beta$ secretion (107). TGF- $\beta$ promotes induction of Th3 cells and this can be further enhanced by the presence of IL-4 and IL-10 $(119,120)$.

$\mathrm{IL}-10$ and TGF- $\beta$ are important in the generation of $\operatorname{Tr} 1$ and Th3 cells. In the presence of IL-10 and IFN- $a$, CD4+ cells differentiate into $\operatorname{Tr} 1$ cells (115). Tr1 cells can produce excessive amounts of IL-10, whereas Th3 cells preferentially produce TGF- $\beta$ (107). IL-10 promotes differentiation of $\operatorname{Tr} 1$ cells, whereas TGF- $\beta$ induces both CD4+CD25+ and CD4+CD25- cells to differentiate into CD4+CD25+ regulatory cells (119). Repeated stimulation of CD4+ cells by immature DCs leads to emergence of regulatory cells, producing IL10 and related to $\operatorname{Tr} 1$ cells (116). Activated $\operatorname{Tr} 1$ and Th3 cells suppress DC stimulatory properties and might induce tolerogenic $\mathrm{DC}$, thus promoting differentiation of naïve CD4+ cells into Tr1 cells (107).

Naturally occurring CD4+ regulatory $T$ cells form $5 \%$ to $15 \%$ of all CD4+ cells in the thymus and constitutively express a-chain of the IL-2 receptor (CD25) and express T cell memory phenotype $(107,121)$. They show weak sensitivity to stimulation via antigen receptor (TCR) and inability of IL-2 production. This suppressive effect requires TCR activation and once activated can exert bystander suppression against lymphocytes with a different antigen specificity of MHC haplotype $(107,121)$. Intravenous and oral route of exposure to Ag favors the expansion of CD25+ cells, and this expansion can be due to proliferation of

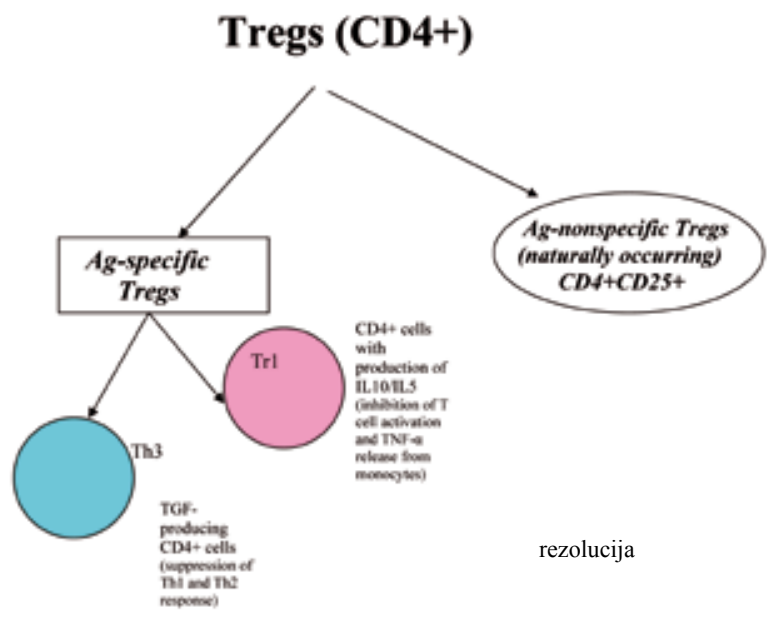

Figure 5. Regulatory cells.

CD4+CD25+ cells or to differentiation of CD4+CD25cells into regulatory cells (121). The ultimate result of suppression with CD25+ cells is inhibition of IL-2 transcription in the responder cell population $(122,123)$. CD4+CD25+ cells inhibit both induction and effector function of T cells (124). APCs have a critical role in the attraction of CD4+CD25+ cells (121).

Transcription factor FoxP3 plays a key role in the development and function of CD4+CD25+ (125). IFNregulatory-factor-1 negatively regulates CD4+CD25+ regulatory $\mathrm{T}$ cell differentiation by repressing Foxp3 expression (126).

CD4+CD25+ cells are able to regulate CD4+ cells, CD8+ cells and B cells. They might be recruited within both secondary lymphoid tissues and inflamed tissue. Their suppressive effect occurs due to direct effect on lymphocytes, even in the absence of APCs; and indirectly due to their effect on APCs through down-regulation of co-stimulatory molecules (CD80 and CD86) (127). Inflammatory stimuli cause DC maturation and this is the key process in directing naïve $T$ cells into effector cells (Th-1 or Th-2), while immature DCs are tolerogenic and favor the development of Tregs (116).

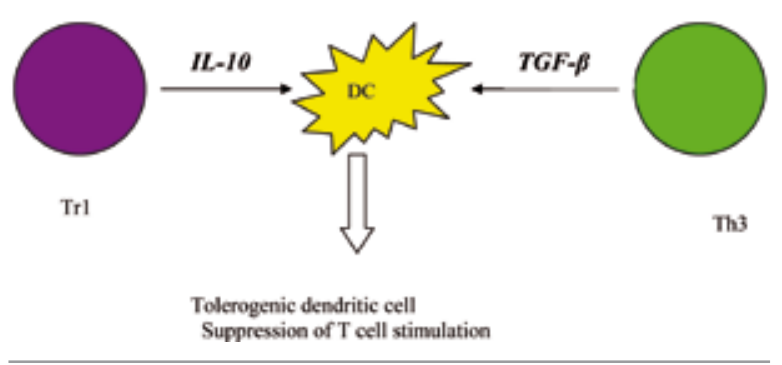

Figure 6. Mechanism of suppressive action of antigen-specific T regulatory lymphocytes. 
The relationship between the CD4+CD25+ cells and $\operatorname{Tr} 1$ is still unclear (121). There is evidence that CD4+CD25+ cells closely cooperate with TGF- $\beta / \mathrm{IL}-10$ cells (probably Tr1 and Th3) (107). CD4+CD25+ can convert conventional CD4+ into Tr1-like regulatory cells or TGF- $\beta$ secreting cells, and therefore their suppression can be due to the following: 1) locally, by contact-dependent induction of T cell anergy, or 2) systemically, by the induction of T regulatory cells via cytokine mediated suppressive activity (121). Once activated, CD4+CD25+ cells produce immunosuppressive cytokines (IL-10, TGF- $\beta$ and less IL-4) $(121,128)$. Suppressor functions can occur via multiple regulatory mechanisms, but it seems that CD4+CD25+ cells exert immunosuppression by cell-cell interaction involving cell surface TGF- $\beta-1$ (128). There is evidence that glucocorticoid-induced TNF receptor seems to be implicated in their suppressive function (129).

CTLA-4 (CD125) is a CD28 homologue expressed on activated $T$ cells and upon interaction with CD80 or CD86 on APC exerts a down-regulatory or attenuating effect on T-cell-mediated immune responses $(130,131)$. CD28/B7 pathway is one of the most important in naïve T-cell activation. CD4+CD25+ T cell activation does not involve the CD28 pathway (130). CD28 engagement increases the expression of the down-modulatory molecule CTLA-4 and induces proliferation of Th- 2 cells with protective function $(132,133)$.

\section{CONCLUSIONS}

Contact allergic dermatitis is a prototype of cell mediated hypersensitivity skin reaction and is the result of complex interactions of numerous immune cells, cytokines and chemokines. Different cell subsets are involved in sensitization and elicitation phases. Dendritic cells with antigen presentation have a central role in the sensitization phase. As the result of their maturation, hapten-specific cells are produced. Memory response is much faster than primary response to allergens and occurs due to the complex interactions of KCs, NKT, B1 cells, mast cells, platelets, endothelium and cytotoxic subsets of cells such as CD8+ and Th-17 cells. The severity and duration of the reaction are controlled by several types of regulatory lymphocytes. Knowledge about the immunology of contact allergic dermatitis gives us an insight into the wide spectrum of the possible therapeutic targets that can be exploited in the future.

\section{References}

1. Vocanson $M$, Hennino $A$, Rozières $A$, Poyet $G$, Nicolas JF. Effector and regulatory mecha- nisms in allergic contact dermatitis. Allergy 2009;64:1699-714.

2. Gober MD, Gaspari AA. Allergic contact dermatitis. Curr Dir Autoimmun 2008;10:1-26.

3. Cavani A. Immune regulatory mechanisms in allergic contact dermatitis and contact sensibilization. Chem Immunol Allergy 2008;94:93-100.

4. Girolomoni G, Gisondi P, Ottaviani C, Cavani A. Immunoregulation of allergic contact dermatitis. J Dermatol 2004;31:264-70.

5. Larsen JM, Geisler C, Nielsen MW, Boding L, Von Essen $M$, Hansen AK, et al. Cellular dynamics in the draining lymph nodes during sensitization and elicitation phases of contact hypersensitivity. Contact Dermatitis 2007;57:300-8.

6. Krasteva M, Kehren J, Ducluzeau MT, Sayag M, Cacciapuoti $\mathrm{M}$, Akiba $\mathrm{H}$, et al. Contact dermatitis I. Pathophysiology of contact sensitivity. Eur J Dermatol 1999;9:65-77.

7. Saint-Mezard P, Krasteva M, Chavagnac C, Bosset $\mathrm{S}$, Akiba H, Kehren J, et al. Afferent and efferent phases of allergic contact dermatitis (ACD) can be induced after a single skin contact with haptens: evidence using a mouse model of primary ACD. J Invest Dermatol 2003;120:641-7.

8. Smith Pease CK, Basketter DA, Patlewicz GY. Contact allergy: the role of skin chemistry and metabolism. Clin Exp Dermatol 2003;28:177-83.

9. Basketter D, Dooms-Goossens A, Karlberg AT, Lepoittevin JP. The chemistry of contact allergy: why is a molecule allergenic? Contact Dermatitis 1995;32:65-73.

10. Lepoittevin JP. Metabolism versus chemical transformation or pro-versus prehaptens? Contact Dermatitis 2006;54:73-4.

11. Vocanson M, Hennino A, Cluzel-Tailhardat $M$, Saint-Mezard P, Benetiere J, Chavagnac C, et al. CD8+ cells are effector cells of contact dermatitis to common skin allergens in mice. J Invest Dermatol 2006;126:815-20.

12. Zaba LC, Krueger JG, Lowes MA. Resident and "inflammatory" dendritic cells in human skin. J Invest Dermatol 2009;129:302-8.

13. Ryan CA, Gerberick GF, Gildea LA, Hulette BC, Betts $C J$, Cumberbatch $M$, et al. Interactions of contact allergens with dendritic cells: opportunities and challenges for the development of novel approaches to hazard assessment. Toxicol Sci 2005;88:4-11.

14. Sasaky Y, Aiba S. Dendritic cells and contact dermatitis. Clin Rev Allergy Immunol 2007;33:27-34. 
15. Allan RS, Waithman J, Bedoui S, Jones CM, Villadangos JA, Zhan $Y$, et al. Migratory dendritic cells transfer antigen to a lymph node-resident dendritic cell population for efficient CTL priming. Immunity 2006;25:153-62.

16. Arrighi JF, Rebsamen M, Rousset F, Kindler V, Hauser C. A critical role for p38 mitogen-activated protein kinase in the maturation of humanblood derived dendritic cells induced by lipopolysaccharide, TNF-alpha and contact sensitizers. J Immunol 2001;166:3837-45.

17. Grabbe S, Steinbrink K, Steinert M, Luger TA, Schwarz T. Removal of the majority of epidermal Langerhans cells by topical or systemic steroid application enhances the effector phase of murine contact hypersensitivity. J Immunol 1995; 155:4207-17.

18. Cella M, Engering A, Pinet V, Pieters J, Lanzavecchia A. Inflammatory stimuli induce accumulation of MHC class II complexes on dendritic cells. Nature 1997;388:782-7.

19. Jonuleit $H$, Kühn $U$, Müller $G$, Steinbrink $K, P a-$ ragnik $L$, Schmitt $E$, et al. Pro-inflammatory cytokines and prostaglandins induce maturation of potent immunostimulatory dendritic cells under fetal calf serum-free conditions. Eur J Immunol 1997;27:3135-42.

20. Aiba S, Terunuma A, Manome H, Tagami H. Dendritic cells respond differently to haptens and irritants by their production of cytokines and expression of co-stimulatory molecules. Eur J Immunol 1997;27:3031-8.

21. Megherbi R, Kiorpelidou E, Foster B, Rowe C, Naisbitt DJ, Goldring CE, Park BK. Role of protein haptenation in triggering maturation events in the dendritic cell surrogate cell line THP-1. Toxicol Appl Pharmacol 2009;238:120-32.

22. Mizuashi M, Ohtani T, Nakagawa S, Aiba S. Redox imbalance induced by contact sensitizers triggers the maturation of dendritic cells. J Invest Dermatol 2005;124:579-86.

23. Martin SF, Dudda JC, Bachtanian E, Lembo A, Liller S, Dürr C. Toll-like receptor and IL-12 signaling control susceptibility to contact dermatitis. J Exp Med;205:2151-62.

24. Schwarzenberger K, Udey MC. Contact allergens and epidermal pro-inflammatory cytokines modulate Langerhans cell E-cadherin expression in situ. J Invest Dermatol 1996;106:553-8.

25. Aiba S, Nakagawa S, Ozawa H, Miyake K, Yagita $\mathrm{H}$, Tagami $\mathrm{H}$. Up-regulation of alfa 4 integrin on activated Langerhans cells: analysis of adhesion molecules on Langerhans cells relating to their migration from skin to draining lymph node. J Invest Dermatol 1993;100:143-7.

26. Jakob T, Udey MC. Regulation of E-cadherinmediated adhesion in Langerhans cell-like dendritic cells by inflammatory mediators that mobilize Langerhans cells in vivo. J Immunol 1998;160:4067-73.

27. Nakae $S$, Naruse-Nakajima C, Sudo K, Horai R, Asano $M$, Iwakura Y. IL-1a, but not IL-1 $\beta$ is required for contact allergen-specific T cell activation during the sensitization phase in contact hypersensitivity. Int Immunol 2001;13:1471-8.

28. Nakae S, Asano M, Horai R, Sakaguchi N, Iwakura Y. IL-1 enhances T-cell dependent antibody production through induction of CD40 ligand and OX40 on T cells. J Immunol 2001;167:90-7.

29. Freudenberg MA, Esser PR, Jakob T, Galanos C, Martin SF. Innate and adaptive immune responses in contact dermatitis: analogy with infections. G Ital Dermatol Venereol 2009;144:17385.

30. He D, Wu L, Kim HK, Li H, Elmets CA, Xu H. IL-17producing $T$ cells are important in effector functions for the elicitation of contact hypersensitivity responses. J Immunol 2006 15;177:6852-8.

31. Jin H, Kumar L, Mathias C, Zurakowski D, Oettgen $\mathrm{H}$, Gorelik $\mathrm{L}$, et al. Toll-like receptor is important for $\mathrm{T}(\mathrm{H}) 1$ response to cutaneous sensitization. J Allergy Clin Immunol 2009;123:875-82.

32. Askenase PW, Itakura A, Leite-de-Moraes MC, Lisbonne M, Roongapinun S, Goldstein DR, et al. TLR-dependent IL-4 production by invariant Valpha14+Jalpha18+ NKT cells to initiate contact sensitivity in vivo. Jlmmunol 2005;175:6390401.

33. Yusuf $N$, Nasti TH, Huang CM, Huber BS, Jaleel $\mathrm{T}$, Lin HY, et al. Heat shock proteins HSP27 and HSP70 are present in the skin and are important mediators of allergic contact hypersensitivity. J Immunol 2009;182:675-83.

34. Saint-Mezard $P$, Berard F, Dubois B, Kaiserlian D, Nicolas JF. The role of CD4+ and CD8+ T cells in contact hypersensitivity and allergic contact dermatitis. Eur J Dermatol 2004;14:131-8.

35. Xu H, Dilulio NA, Fairchild RL. T cell populations primed by hapten sensitization in contact sensitivity are distinguished by polarized patterns of cytokine production: interferon gamma-producing (Tc1) effector CD8+ T cells and interleukin (II) 4/Il-10-producing (Th2) negative regulatory CD4+ T cells. J Exp Med 1996;183:1001-12. 
36. Xu H, Heeger PS, Fairchild RL. Distinct roles for B7-1 and B7-2 determinants during priming of effector CD8+ Tc1 and regulatory CD4+ Th2 cells for contact hypersensitivity. J Immunol 1997;159: 4217-26.

37. Greenwald RJ, Freeman GJ, Sharpe AH.The B7 family revisited. Annu Rev Immunol 2005;23:51548.

38. Kim HK, Guan H, Zu G, Li H, Wu L, Feng X. Highlevel expression of $\mathrm{B} 7-\mathrm{H} 1$ molecules by dendritic cells suppresses the function of activated $T$ cells and desensitizes allergen-primed animals. J Leukoc Biol 2006;79:686-95.

39. Burns R, Luzina I, Nasir A, Haidaris CG, Barth RK, Gaspari AA. Keratinocyte-derived, CD80-mediated costimulation is associated with haptenspecific $\lg \mathrm{E}$ production during contact hypersensitivity to TH1 haptens. J Allergy Clin Immunol 2005;115:383-90.

40. Gorbachev AV, Heeger PS, Fairchild RL. CD4+ and CD8+ T cell priming for contact hypersensitivity occurs independently of CD40-CD154 interactions. J Immunol 2001;166:2323-32.

41. Chen Al, McAdam AJ, Buhlmann JE, Scott S, Lupher ML Jr, Greenfield EA, et al. OX40-ligand has a critical costimulatory role in dendritic cell: T cell interactions. Immunity 1999;11:689-98.

42. Grewal IS, Flavell RA. The role of CD40 ligand in costimulation and T-cell activation. Immunol Rev 1996;153:85-106.

43. Schönbeck U, Libby P. The CD40/CD154 receptor/ligand dyad. Cell Mol Life Sci 2001;58:4-43.

44. Xu Y, Song G. The role of CD40/CD154 interaction in cell immunoregulation. J Biomed Sci 2004;11:426-38.

45. Quezada SA, Jarvinen LZ, Lind EF, Noelle RJ. CD40/CD154 interactions at the interface of tolerance and immunity. Annu Rev Immunol 2004;22:307-28.

46. Miga AJ, Masters SR, Durell BG, Gonzalez M, Jenkins MK, Maliszewski $C$, et al. Dendritic cell longevity and $\mathrm{T}$ cell persistence is controlled by CD154-CD40 interactions. Eur J Immunol 2001;31:959-65.

47. Gorbachev AV, Dilulio NA, Fairchild RL. IL-12 augments CD8+ cell development for contact sensitivity responses and circumvents antiCD154 antibody-mediated inhibition. J Immunol 2001;167:156-62.

48. Li L, Sad S, Kägi D, Mosmann TR. CD8Tc1 and Tc2 cells secrete distinct cytokine patterns in vi- tro and in vivo but induce similar inflammatory reactions. J Immunol 1997;158:4152-61.

49. Sabatté J, Maggini J, Nahmod K, Amaral MM, Martínez D, Salamone G. Interplay of pathogens, cytokines and other stress signals in the regulation of dendritic cell function. Cytokine Growth Factor Rev 2007; 18:5-17.

50. Martin S, Delattre V, Leicht C, Weltzien HU, Simon JC. A high frequency of allergen-specific CD8+ Tc1 cells is associated with the murine immune response to the contact sensitizer trinitrophenyl. Exp Dermatol 2003;12:78-85.

51. Ebert LM, Schaerli P, Moser B. Chemokine-mediated control of T cell traffic in lymphoid and peripheral tissues. Mol Immunol 2005;42:799-809.

52. Sallusto F, Lenig D, Förster R, Lipp M, Lanzavecchia A. Two subsets of memory $T$ lymphocytes with distinct homing potentials and effector functions. Nature 1999;401:708-12.

53. Walzer T, Marçais A, Saltel F, Bella C, Jurdic P, Marvel J. Cutting edge: immediate RANTES secretion by restricting memory CD8 T cells following antigenic stimulation. J Immunol 2003;170:1615-9.

54. Santamaria-Babí LF. CLA(+) T cells in cutaneous diseases. Eur J Dermatol 2004;14:13-8.

55. Smithson G, Rogers $C E$, Smith PL, Scheidegger $E P$, Petryniak $B$, Myers JT, et al. Fuc-TVII is required for T-helper and T-cytotoxic 1 lymphocyte selectin ligand expression and recruitment in inflammation, and together with Fuc-TIV regulates naïve $T$ cell trafficking to lymph nodes. J Exp Med 2001;194:601-14.

56. Cavani A, Nasorri F, Prezzi C, Sebastiani S, Albanesi C, Girolomoni G. Human CD4+ T lymphocytes with remarkable regulatory functions on dendritic cells and nickel-specific Th1 immune responses. J Invest Dermatol 2000;114:295-302.

57. Akiba H, Kehren J, Ducluzeau MT, Krasteva M, Horand F, Kaiserlian D, et al. Skin inflammation during contact hypersensitivity is mediated by early recruitment of CD8+ cytotoxic 1 cells inducing keratinocyte apoptosis. J Immunol 2002; 168:3079-87.

58. Gorbachev AV, Fairchild RL. CD4+ cells regulate CD8+ cell-mediated cutaneous immune responses by restricting effector $\mathrm{T}$ cell development through a Fas ligand-dependent mechanism. J Immunol 2004;172:2286-95.

59. Gorbachev AV, Fairchild RL. Regulatory role of CD4+ T cells during the development of contact hypersensitivity responses. Immunol Res 2001;24:69-77. 
60. Tsuji RF, Kawikova I, Ramabhadran R, AkahiraAzuma M, Taub D, Hugli TE. Early local generation of $\mathrm{C} 5 \mathrm{a}$ initiates the elicitation of contact sensitivity by leading to early $T$ cell recruitment. J Immunol 2000;165:1588-98.

61. Borges E, Tietz W, Steegmaier M, Moll T, Hallmann R, Hamann A, et al. P-selectin glycoprotein ligand-1 (PSGL-1) on $T$ helper 1 but not on T helper 2 cells binds to P-selectin and supports migration into inflamed skin. J Exp Med 1997; 185:573-8.

62. Xie H, Lim YC, Luscinskas FW, Lichtman AH. Acquisition of selectin binding and peripheral homing properties by CD4+ and CD8+ cells. J Exp Med 1999;189:1765-76.

63. Goebeler M, Trautmann A, Voss A, Bröcker EV, Toksoy A, Gillitzer R. Differential and sequential expression of multiple chemokines during elicitation of allergic contact hypersensitivity. Am J Pathol 2001;158:431-40.

64. Askenase PW. Yes T cells, but three different T cells (alphabeta, gammadelta and NK T cells), and also B-1 cells mediate contact sensitivity. Clin Exp Immunol 2001;125:345-50.

65. Godfrey DI, Hammond KJ, Poulton LD, Smyth MJ, Baxter AG. NKT cells: facts, functions and fallacies. Immunol Today 2000;21:573-83.

66. Campos RA, Szczepanik M, Lisbonne M, Itakura A, Leite-de-Moraes M, Askenase PW. Invariant NKT cells rapidly activated via immunization with diverse contact antigens collaborate in vitro with B1-cells to initiate contact sensitivity. J Immunol 2006;177:3686-94.

67. Campos RA, Szczepanik M, Itakura A, AkahiraAzuma M, Sidobre S, Kronenberg M, et al. Cutaneous immunization rapidly activates liver invariant Valpha14 NKT cells stimulating B-1 B cells to initiate $T$ cell recruitment for elicitation of contact sensitivity. J Exp Med 2003;198:178596.

68. Campos RA, Szczepanik M, Itakura A, Lisbonne $M$, Dey N, Leite-de-Moraes MC, et al. Interleukin-4-dependent innate collaboration between iNKT cells and B-1 B cells controls adaptive contact sensitivity. Immunology 2006;117:536-47.

69. Askenase PW, Tsuji RF. B1 B cell IgM antibody initiates T cell elicitation of contact sensitivity. Curr Top Microbiol Immunol 2000;252:171-7.

70. Szczepanik $M$, Akahira-Azuma $M$, Bryniarski $\mathrm{K}$, Tsuji RF, Kawikova I, Ptak W, et al. B-1 B cells mediate required early $T$ cell recruitment to eli- cit protein-induced delayed-type hypersensitivity. J Immunol 2003;171:6225-35.

71. Tsuji RF, Geba GP, Wang Y, Kawamoto K, Matis LA, Askenase PW. Required early complement activation in contact sensitivity with generation of local C5-dependent chemotactic activity, and late T cell IFN- $\gamma$ : a possible role of B cells. J Exp Med 1997;186:1015-26.

72. Tsuji RF, Kikuchi M, Askenase PW. Possible involvement of $\mathrm{C} 5 / \mathrm{C} 5 \mathrm{a}$ in the efferent and elicitation phases of contact sensititivity. J Immunol 1996;156:4444-50.

73. Geba GP, Ptak W, Anderson GM, Paliwal V, Ratzlaff RE, Levin J. Delayed-type hypersensitivity in mast cell deficient mice: dependence on platelets for expression of contact sensitivity. J Immunol 1996;157:557-65.

74. Matsuda H, Ushio H, Geba GP, Askenase PW. Human platelets can initiate $T$ cell-dependent contact sensitivity through local serotonin release mediated by IgE antibodies. J Immunol 1997;158:2891-7.

75. Kobayashi M, Nunomura S, Gon Y, Endo D, Kishiro S, Fukunaga M. Abrogation of high-affinity IgE receptor-mediated mast cell activation at the effector phase prevents contact hypersensitivity to oxazolone. J Invest Dermatol 2009 Sep 10. [Epub ahead of print]

76. van Loveren $\mathrm{H}$, Meade R, Askenase PW. An early component of delayed-type hypersensitivity mediated by $\mathrm{T}$ cells and mast cells. J Exp Med 1983;157:1604-17.

77. Nakae S, Komiyama Y, Narumi S, Sudo K, Horai R, Tagawa $Y$, et al. IL-1-induced tumor necrosis factor-a elicits inflammatory cell infiltration in the skin by inducing IFN- $\gamma$-inducible protein 10 in the elicitation phase of contact hypersensitivity response. Int Immunol 2003;15:251-60.

78. Grabbe S, Steinert M, Mahnke K, Schwartz A, Luger TA, Schwarz T. Dissection of antigenic and irritative effects of epicutaneously applied haptens in mice: evidence that not the antigenic component but nonspecific proinflammatory effects of haptens determine the concentration-dependent elicitation of allergic contact dermatitis. J Clin Invest 1996;98:1158-64.

79. McHale JF, Harari OA, Marshall D, Haskard DO. Vascular endothelial cell expression of intercellular adhesion molecule-1 and vascular cell adhesion molecule -1 at the onset of eliciting contact hypersensitivity in mice: evidence for dominant role of TNF- a. J Immunol 1999;162:1648-55. 
80. Grabbe S, SchwarzT. Immunoregulatory mechanisms involved in elicitation of allergic contact hypersensitivity. Immunol Today 1998;19:37-44.

81. Albanesi C, Scarponi C, Sebastiani S, Cavani A, Federici M, Sozzani S, Girolomoni G. A cytokineto-chemokine axis between $\mathrm{T}$ lymphocytes and keratinocytes can favor Th 1 cell accumulation in chronic inflammatory skin diseases. J Leukoc Biol 2001;70:617-23.

82. Traidl C, Sebastiani S, Albanesi C, Merk HF, Puddu P, Girolomoni G, et al. Disparate cytotoxic activity of nickel-specific CD8+ and CD4+ T cell subsets against keratinocytes. J Immunol 2000;165:3058-64.

83. Harari OA, McHale JF, Marshall D, Ahmed S, Brown D, Askenase PW, et al. Endothelial cell $\mathrm{E}$ - and P-selectin up-regulation in murine contact sensitivity is prolonged by distinct mechanisms occurring in sequence. J Immunol 1999;163:6860-6.

84. Santamaria Babi LF, Perez Soler MT, Hauser C, Blaser K. Skin-homing T-cells in human cutaneous allergic inflammation. Immunol Res 1995; 14:317-24.

85. Hwang JM, Yamanouchi J, Santamaria P, Kubes P. A critical temporal window for selectin-dependent CD4+ lymphocyte homing and initiation of late-phase inflammation in contact sensitivity. J Exp Med 2004;199:1223-34.

86. Dufour JH, Dziejman M, Liu MT, Leung JH, Lane TE, Luster AD. IFN- $\gamma$-inducible protein 10 (IP-10; CXCL-10)-deficient mice revealed a role for IP-10 in effector T cell generation and trafficking. J Immunol 2002;168:3195-204.

87. Santamaria Babi LF, Moser B, Perez Soler MT, Moser R, Loetscher P, Villiger B. The interleukin8 receptor $B$ and $C X C$ chemokines can mediate transendothelial migration of human skin homing T cells. Eur J Immunol 1996;26:2056-61.

88. Campbell JJ, Haraldsen G, Pan J, Rottman J, Qin $\mathrm{S}$, Ponath $\mathrm{P}$, et al. The chemokine receptor CCR4 in vascular recognition by cutaneous but not intestinal memory T cells. Nature 1999;400:77680.

89. Homey B, Dieu-Nosjean MC, Wiesenborn A, Massacrier C, Pin JJ, Oldham E, et al. Up-regulation of macrophage inflammatory protein 3 alpha/CCL20 and CC chemokine receptor 6 in psoriasis. J Immunol 2000;164:6621-32.

90. Rottman JB, Smith TL, Ganley KG, Kikuchi T, Krueger JG. Potential role of the chemokine receptors CXCR3, CCR4, and the integrin alphaE- beta7 in the pathogenesis of psoriasis. Lab Invest 2001;81:335-47.

91. Homey B, Wang W, Soto $H$, Buchanan ME, Wiesenborn A, Catron D, et al. Cutting edge: the orphan chemokine receptor $G$ protein-coupled receptor-2 (GPR-2, CCR10) binds the skin-associated chemokine CCL27 (CTACK/ALP/ILC). J Immunol 2000;164:3465-70.

92. Morales J, Homey B, Vicari AP, Hudak S, Oldham E, Hedrick J, et al. CTACK, a skin-associated chemokine that preferentially attracts skin-homing memory T cells. Proc Natl Acad Sci U S A 1999;96:14470-5.

93. Moser B, Loetscher P. Lymphocyte traffic control by chemokines. Nat Immunol 2001;2:123-8.

94. Nakamura K, Williams IR, Kupper TS. Keratinocyte-derived monocyte chemoattractant protein 1 (MCP-1): analysis in a transgenic model demonstrates MCP-1 can recruit dendritic and Langerhans cells to skin. J Invest Dermatol 1995;105:635-43.

95. Mizumoto N. Analysis of contact hypersensitivity response in human monocyte chemoattractant protein-1 (MCP-1) transgenic mice. Hokkaido Igaku Zasshi 1999;74:199-216.

96. Mizumoto $N$, Iwabichi K, Nakamura $H$, Ato $M$, Shibaki A, Kawashima T, et al. Enhanced contact hypersensitivity in human monocyte chemoattractant protein-1 transgenic mouse. Immunobiology 2001;204:477-93.

97. Paradis TJ, Cole SH, Nelson RT, Gladue RP. Essential role of CCR6 in directing activated T cells to the skin during contact hypersensitivity. J Invest Dermatol 2008;128:628-33.

98. Reiss $Y$, Proudfoot AE, Power CA, Campbell JJ, Butcher EC. CC chemokine receptor (CCR)4 and the CCR10 ligand cutaneous T-cell attracting chemokine (CTACK) in lymphocyte. J Exp Med 2001;194:1541-7.

99. Zhao Y, Balato A, Fishelevich R, Chapoval A, Mann DL, Gaspari AA. Th17/Tc17 infiltration and associated cytokine expression in elicitation phase of allergic contact dermatitis. Br J Dermatol 2009;161: 1301-6.

100. Yao C, Sakata D, Esaki Y, Li Y, Matsuoka T, Kuroiwa $\mathrm{K}$, et al. Prostaglandin E2-EP4 signaling promotes immune inflammation through Th1 cell differentiation and Th17 cell expansion. Nat Med 2009;15:633-40.

101. Boniface $\mathrm{K}$, Bak-Jensen KS, Li Y, Blumenschein WM, McGeachy MJ, McClanahan TK, et al. Prostaglandin E2 regulates Th17 cell differentiation 
and function through cyclic AMP and EP2/EP4 receptor signaling. J Exp Med 2009;206:535-48.

102. Khayrullina $\mathrm{T}$, Yen $\mathrm{JH}$, Jing $\mathrm{H}$, Ganea D. In vitro differentiation of dendritic cells in the presence of prostaglandin E2 alters the IL-12/IL-23 balance and promotes differentiation of Th17 cells. J Immunol 2008;181:721-35.

103. Larsen JM, Bonefeld CM, Poulsen SS, Geisler C, Skov L. IL-23 and T(H)17-mediated inflammation in human allergic contact dermatitis. Allergy Clin Immunol 2009;123:486-92.

104. Korn T, Bettelli E, Oukka M, Kuchroo VK. IL-17 and Th 17 cells. Annu Rev Immunol 2009;27:485517.

105. Awasthi A, Kuchroo VK. Th17 cells: from precursors to players in inflammation and infection. Int Immunol 2009;21:489-98.

106. Trautmann A, Akdis M, Kleemann D, Altznauer F, Simon HU, Graeve T, et al. T-cell mediated Fasinduced keratinocyte apoptosis plays a key pathogenetic role in eczematous dermatitis. J Clin Invest 2000;106:25-35.

107. Jonuleit $H$, Schmitt $E$. The regulatory $T$ cell family: distinct subsets and their interactions. J Immunol 2003;171:6323-7.

108. Chan SH, Cosgrove D, Waltzinger C, Benoist C, Mathis D. Another view of the selective model of thymocyte selection. Cell 1993;73:225-36.

109. Desvignes C, Etchart N, Kehren J, Akiba I, Nicolas JF, Kaiserlian D. Oral administration of hapten inhibits in vivo induction of specific cytotoxic CD8+ $T$ cells mediating tissue inflammation: a role for regulatory CD4+ T cells. J Immunol 2000;164:2515-22.

110. Yanaba K, Bouaziz JD, Matsushita T, Tsubata T, Tedder TF. The development and function of regulatory B cells expressing IL-10 (B10 cells) requires antigen receptor diversity and TLR signals. J Immunol 2009;182:7459-72.

111. Bouaziz JD, Yanaba K, Tedder TF. Regulatory B cells as inhibitors of immune responses and inflammation. Immunol Rev 2008;224:201-14.

112. Minang JT, Areström I, Zuber B, Jönsson G, Troye-Blomberg M, Ahlborg N. Nickel-induced IL-10 down-regulates Th1- but not Th2-type cytokine responses to the contact allergen nickel. Clin Exp Immunol 2006;143:494-502.

113. Kemper C, Chan AC, Green JM, Brett KA, Murphy $\mathrm{KM}$, Atkinson JP. Activation of human CD4+ cells with CD3 and CD46 induces a T regulatory cell 1 phenotype. Nature $2003 ; 421: 388-92$.
114. Steinbrink K, Wölfl $M$, Jonuleit $H$, Knop J, Enk AH. Induction of tolerance by IL-10-treated dendritic cells. J Immunol 1997;159:4772-80.

115. Levings MK, Sangregorio R, Galbiati F, Squadrone S, de Waal Malefyt R, Roncarolo MG. IFN- $a$ and IL-10 induce the differentiation of human type I T regulatory cells. J Immunol 2001;166:5530-9.

116. Jonauleit H, Schmitt E, Schuler G, Knop J, Enk $\mathrm{AH}$. Induction of interleukin 10-producing nonproliferating CD4(+) T cells with regulatory properties by repetitive stimulation with allogeneic immature human dendritic cell. J Exp Med 2000;192:1213-22.

117. Jonuleit H, Schmitt E, Steinbrink K, Enk AH. Dendritic cells as a tool to induce anergic and regulatory T cells. Trends Immunol 2001;22:394-400.

118. Groux H, O'Garra A, Bigler M, Rouleau M, Antonenko $S$, de Vries JE. A CD4+T cell subset inhibits antigen-specific T-cell responses and prevents colitis. Nature 1997;389:737-42.

119. Yamagiwa S, Gray JD, Hashimoto S, Horwitz DA. A role of TGF- $\beta$ in the generation and expansion of CD4+CD25+ regulatory $T$ cells from human peripheral blood. J Immunol 2001;166:7282-9.

120. Weiner $\mathrm{HL}$. Induction and mechanism of action of transforming growth factor- $\beta$-secreting Th3 regulatory cells. Immunol Rev 2001;182:207-14.

121. Dubois B, Chapat L, Goubier A, Kaiserlian D. CD4+CD25+T cells as key regulators of immune responses. Eur J Dermatol 2003;13:111-6.

122. Apostolou I, Sarukhan A, Klein L, von Boehmer $\mathrm{H}$. Origin of regulatory $T$ cells with known specificity for antigen. Nat Immunol 2002;3:756-63.

123. Thornton AM, Shevach EM. CD4+CD25+ immunoregulatory $T$ cells suppress polyclonal $T$ cell activation in vitro by inhibiting interleukin 2 production. J Exp Med 1998;188:287-96.

124. Suri-Payer $E$, Amar AZ, Thornton AM, Shevach EM. CD4+CD25+ T cells inhibit both the induction and effector function of autoreactive T cells and represent a unique lineage of immunoregulatory cells. J Immunol 1998;160:1212-8.

125. Fontenot JD, Gavin MA, Rudensky AY. Foxp3 programs the development and function of CD4+CD25+ regulatory $T$ cells. Nat Immunol 2003;4:330-6.

126. Fragale A, Gabriele L, Stellacci E, Borghi P, Perrotti $E$, Ilari $R$. IFN regulatory factor-1 negatively regulates CD4+ CD25+ regulatory $T$ cell differentiation by repressing Foxp3 expression. J Immunol 2008;181:1673-82. 
127. Cederbom L, Hall H, Ivars F. CD4+CD25+ regulatory $\mathrm{T}$ cells down-regulate costimulatory molecules on antigen-presenting cells. Eur J Immunol 2000;30:1538-43.

128. Nakamura K, Kitani A, Strober W. Cell-contact-dependent immunosuppression by CD4(+)CD25(+) regulatory T cells is mediated by cell surface-bound transforming growth factor beta. J Exp Med 2001;194:629-44.

129. McHugh RS, Whitters MJ, Piccirillo CA, Young DA, Shevach EM, Collins M. CD4+CD25+ immunoregulatory $T$ cells: gene expression analysis reveals a functional role for the glucocorticoid-induced TNF receptor. Immunity 2002;16:311-23.

130. Takahashi T, Tagami T, Yamazaki S, Uede T, Shimizu J, Sakaguchi N. Immunologic self-tole- rance maintained by $\mathrm{CD} 25(+) \mathrm{CD} 4(+)$ regulatory $\mathrm{T}$ cells constitutively expressing cytotoxic T lymphocyte-associated antigen 4. J Exp Med 2000;192:303-10.

131. Coenen JJ, Koenen HJ, van Rijssen E, Boon L, Joosten I, Hilbrands LB. CTLA-4 engagement and regulatory $\mathrm{CD} 4+\mathrm{CD} 25+\mathrm{T}$ cells independently control CD8+-mediated responses under costimulation blockade. J Immunol 2006;176:52406.

132. Bour-Jordan H, Blueston JA. CD28 function: a balance of costimulatory and regulatory signals. J Clin Immunol 2002;22:1-7.

133. Oosterwegel MA, Greenwald RJ, Mandelbrot DA, Lorsbach RB, Sharpe AH. CTLA-4 and T cell activation. Curr Opin Immunol 1999;11:294-300.

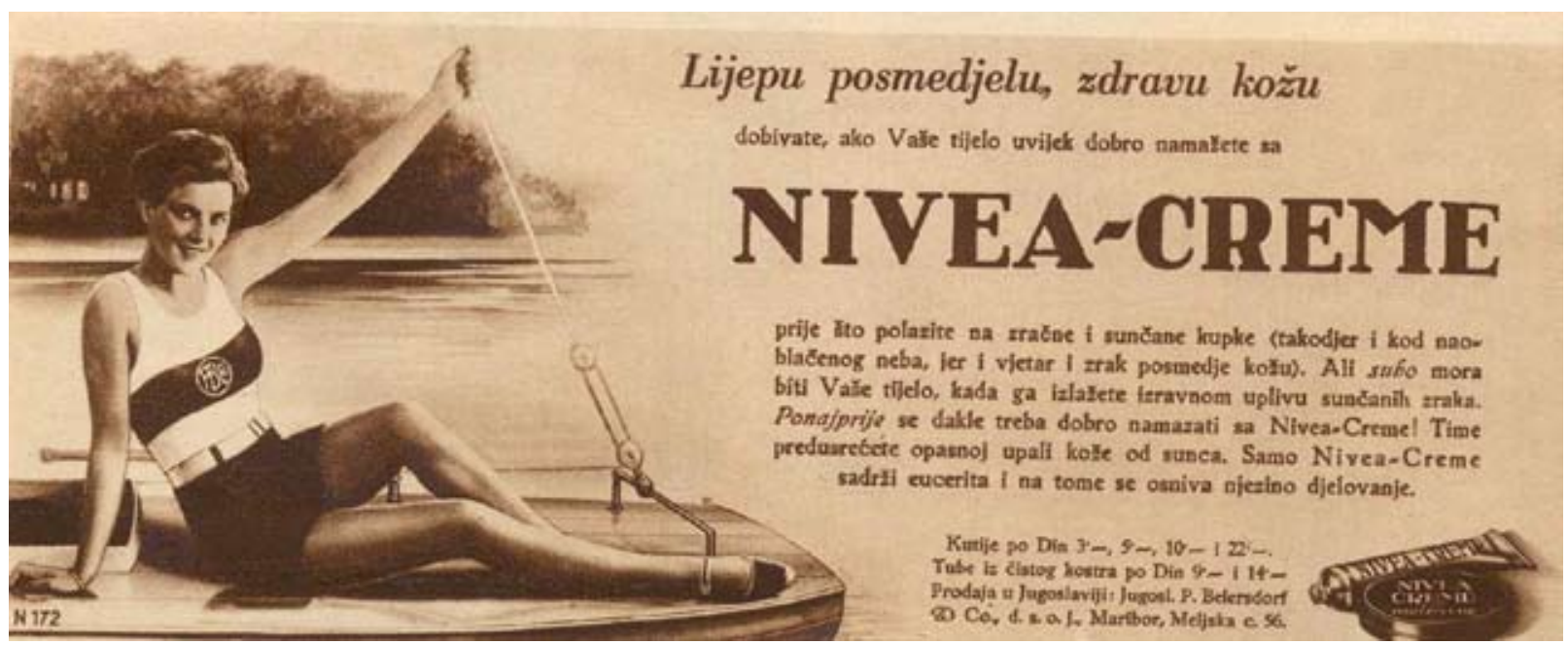

You can have brownish, healthy skin by using Nivea cream; year 1936.

(from the collection of Mr. Zlatko Puntijar) 